\title{
Evaluation of the Effect of Tube Pitch and Surface Alterations on Temperature Field at Sprinkled Tube Bundle
}

\author{
Petr Kracík ${ }^{1, a}$, Tomáš Copek ${ }^{1}$, Martin Zachar $^{1}$ and Jiří Pospíšil ${ }^{1}$ \\ ${ }^{I}$ Institute of Power Engineering, Brno University of Technology, Faculty of Mechanical Engineering, Technická 2896/2, \\ 61669 Brno, The Czech Republic
}

\begin{abstract}
Water flowing on a sprinkled tube bundle forms three basic modes: It is the Droplet mode (liquid drips from one tube to another), the Jet mode (with an increasing flow rate droplets merge into a column) and the Membrane (Sheet) mode (with further increasing of falling film liquid flow rate columns merge and create sheets between the tubes. With sufficient flow rate sheets merge at this state and the tube bundle is completely covered by a thin liquid film). There are several factors influencing the individual mode types as well as heat transfer. Beside the above mentioned falling film liquid flow rate they are for instance tube diameters, tube pitches in a tube bundle or a physical condition of a falling film liquid. This paper presents a summary of data measured at atmospheric pressure at a tube bundle consisting of copper tubes of 12 milimeters diameter and of the studied tube length one meter. The tubes are positioned horizontally one above another with the tested pitches of 15,20,25 and $30 \mathrm{~mm}$ and there is a distribution tube placed above them with water flowing out. The thermal gradient of 15-40 has been tested with all pitches where the falling film liquid's temperature at the inlet of the distribution tube was $15^{\circ} \mathrm{C}$. The liquid was heated during the flow through the exchanger and the temperature of the sprinkled (heater) liquid at the inlet of the exchanger with a constant flow rate about 7.2 litres per minute was $40{ }^{\circ} \mathrm{C}$. The tested flow of the falling film liquid ranged from 1.0 to 13.0 litres per minute. Sequences of 180 exposures have been recorded in partial flow rate stages by thermographic camera with record frequency of $30 \mathrm{~Hz}$ which were consequently assessed using the Matlab programme. This paper presents results achieved at the above mentioned pitches and at three types of tube bundle surfaces.
\end{abstract}

\section{Introduction}

Due to decreasing supply of fossil fuels and their increasing price the minimization of energy consumption becomes first priority, followed by saving of primary fuel entering into energy processes which are supposed to achieve maximum efficiency possible, and last but not least using so called renewable sources of energy. Among so called renewable sources, a biomass combustion technology is mainly used to generate thermal energy and electricity in the Czech Republic. Current research aims to reflect these demands well. For instance research is conducted in the field of optimization of technology for wood mass preparation $[3,4]$ before combustion or further utilization for pellets production. At the Department of Power Engineering long-term research focuses apart from other things on the utilization of waste thermal energy, which is found for example in condensers at large energy units, for possible generation of cool in absorption units.

One of the basic elements of an absorption circuit is an evaporator inside of which the heat-carrier substance is sprayed onto a tube bundle. Due to a low pressure environment inside the container where the bundle is located the falling film liquid at the tube bundle boils. Heat necessary for boiling is derived from a cooled substance flowing inside the tube bundle. The topic of sprinkled tube bundles is detailed in this paper.

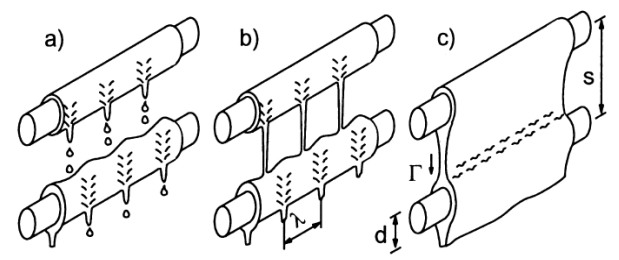

Figure 1 Sprinkle Modes [1]

A liquid flowing through a horizontal tube bundle forms three basic sprinkle modes visible in Figure 1. At a low flow rate the liquid drips from one tube to another in the so called Droplet mode (a). With an increasing flow rate droplets merge and form columns in the Jet mode (b). With a further flow rate increase the columns merge and first from sheets which are with an additional flow rate increase merged together

\footnotetext{
$\overline{{ }^{a} \text { Corresponding author: kracik@fme.vutbr.cz }}$
} 
until they fill in the whole gap between the tubes. That is why this mode is called the Sheet or Membrane mode (c).

Research in the area of sprinkled exchangers can be divided into two major parts. The first part is research on heat transfer and determination of the heat transfer coefficient at sprinkled tube bundles for various liquids, whether boiling or not. For water as the falling film liquid they were for example $[6,7,8,9,11]$. The second part is testing of sprinkle modes for various tube diameters, tube pitches and tube materials and determination of individual modes' interface. This area is mainly researched by $[2,5,10]$.

All results published so far for water as the falling film liquid apply to one to three tubes for which the mentioned relations studied are determined in rigid laboratory conditions defined strictly in advance. The sprinkled tubes were not viewed from the operational perspective where there are more tubes and various modes may occur in different parts with various heat transfer values.

This paper focuses on temperature fields at a sprinkled tube bundle consisting of ten copper tubes and their alterations depending on the change of falling film liquid flow rate, type of the tubes' surface and at various tube bundle pitches. The liquid temperature can be measured by different methods, both contact or contactless. In our case the temperature at a sprinkled tube bundle was determined by means of a thermographic camera.

\section{Measuring Apparatus}

For the purposes of examination of heat transfer and sprinkle modes at sprinkled tube bundles a test apparatus has been constructed; see the diagram at Fig. 2 on the right and its photography on the left.

Falling film liquid of temperature (T1) and volumetric flow rate (V1 - measured by the induction flow meter FM1 - FLOMAG 3000) flows from a distribution tube positioned above the bundle to which a liquid of temperature (T3) and flow rate (V2 - measured by the induction flow meter FM2 - FLOMAG 3000) flows in and a liquid of temperature (T4) flows out into the collection flume positioned below the examined exchanger. The studied area, i.e. the sprinkled area, is one meter wide. There are also four thermocouples (T6-T9) in the loop measuring the process of temperature change within the loop. Falling film liquid below the exchanger is collected into a small flume situated right below the last tube from which the liquid is conducted towards the thermocouple (T4) that measures its temperature and then the liquid freely flows into the collection flume from where it is drawn by a pump the to a drain (C). In case of the excess of hot water it can be let off to a drain through a gate valve (GV6). The sprinkling loop is further fitted with a water meter and rotameter for the purpose of visual inspection. All used thermocouples are insulated and unearthed $\mathrm{T}$ type thermocouples.

All examined liquid temperatures (T1-T9), environment temperature (uninsulated $\mathrm{T}$ type thermocouple) and flow rates $\mathrm{V} 1$ and $\mathrm{V} 2$ are continuously recorded by converters DAQ 56 and saved in a computer in the LabView interface.

A thermographic camera FLIR SC 660 with basic lens of $45^{\circ} \times 34^{\circ} / 0.2 \mathrm{~m}$ field of view was positioned on a tripod in front of an atmospheric stand. The thermographic camera enables to capture sequences of $30 \mathrm{~Hz}$ frequency for the period of 6 seconds
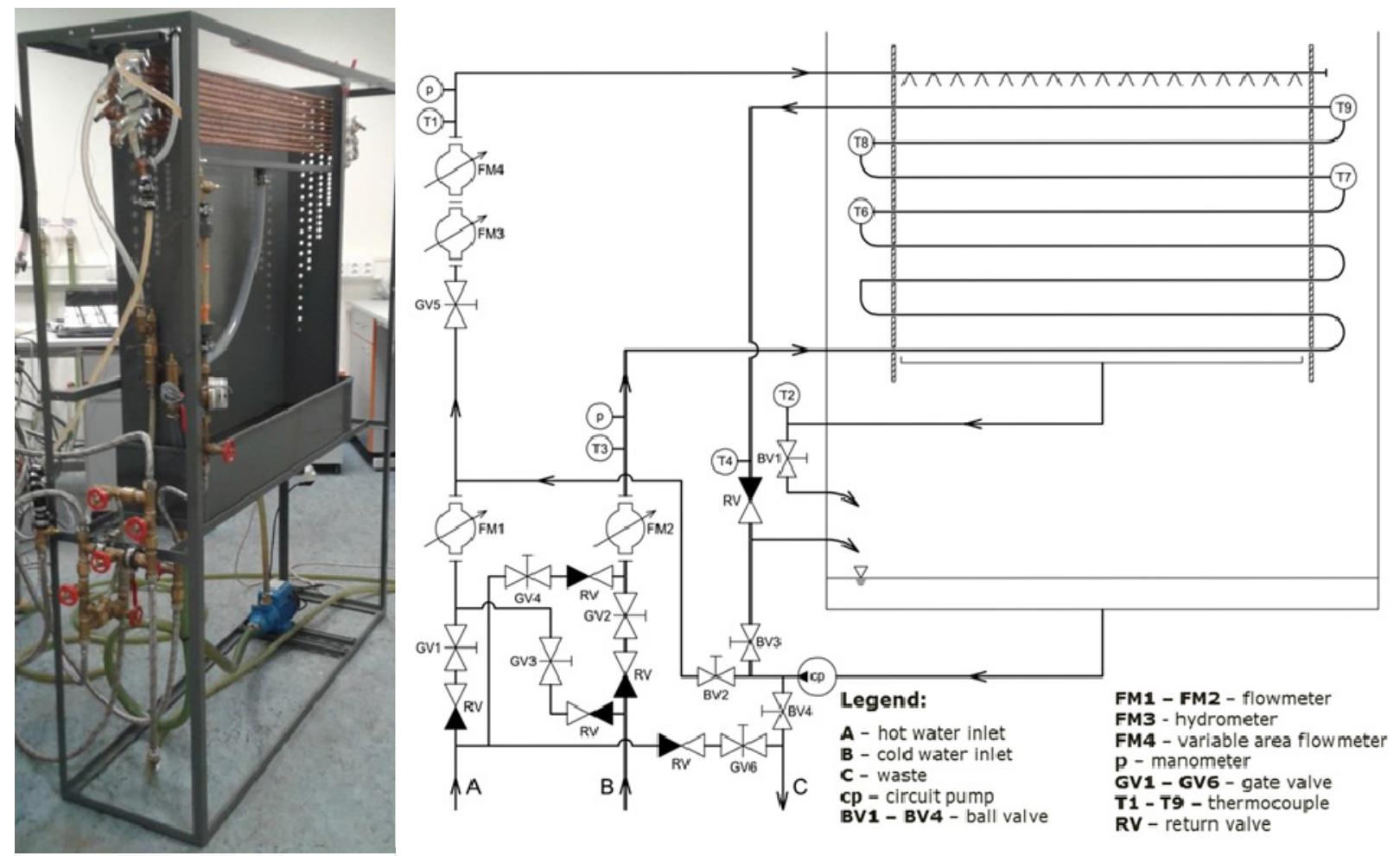

Figure 2 Test Apparatus Photo and Diagram 
with resolution $640 \times 420$ pixels when saving the record to the camera and of up to $60 \mathrm{~Hz}$ frequency and unlimited record duration when saving to a computer.

Apart from the falling film liquid flow rate effect on the examined heat transfer and sprinkle modes the influence of tube surface has also been studied. Fig. 3 on the top shows a clear difference between a smooth surface and a grooved surface with rhombus pattern. This surface has been created by the cold volumetric profiling and track wheeling technique (grooving). The outer tube diameter ranges between $12.3-12.4 \mathrm{~mm}$. The calculations take into account the mean tube diameter of $12.0 \mathrm{~mm}$. Fig. 3 below shows an example of the difference between a smooth and a sandblasted surface.

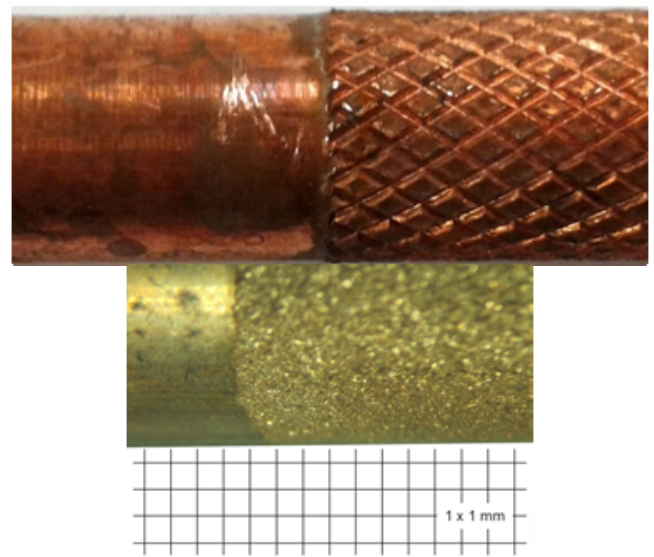

Figure 3 Types of Examined Surfaces following tube pitches were constructed: A1 (15 mm), B1 $(20 \mathrm{~mm}), \mathrm{C} 1(25 \mathrm{~mm})$ and A2 $(30 \mathrm{~mm})$. Regulated input quantities divided according to the sprinkled bundle surface types and tube pitches are summarized in Table 1. In this table "Number" represents the number of captured thermographic sequences at selected flow rates. Then " $t_{1}$ " stands for an average falling film liquid temperature at the distribution tube outlet, " $t_{3}$ " stands for an average temperature of the sprinkled (heater) liquid at the inlet of the exchanger and " $\mathrm{V}_{2}$ " stands for an average flow rate of the sprinkled (heater) liquid. The average value of these quantities was calculated together with standard deviation from partial values measured during sequence capturing and an average standard deviation of the partial measured values is in brackets. The last quantity given is the table is a range of falling film liquid flow rate at which the sequences were captured together with an average standard deviation of the partial flow rates.

Figures 4-6 show points of average heat transfers derived from the cooling liquid in dependence on a falling film liquid flow rate and tube pitch. The total derived heat transfer was calculated on the basis of the temperature at the inlet $\left(\mathrm{t}_{3}\right)$ or outlet $\left(\mathrm{t}_{4}\right)$ of the loop and on the basis of the cooling liquid flow rate $\left(\mathrm{V}_{2}\right)$ at stable conditions. These points correspond to the time when the thermographic camera records were captured. Individual series were connected by a conveniently selected curve highlighting the trend.

\section{Experiments' Results}

For the purpose of experiments described in this paper tube bundles consisting of ten copper tubes of the

Table 1 Average Measured Values of Regulated Quantities

\begin{tabular}{|c|c|c|c|c|c|c|}
\hline & Pitch & Number & $\mathrm{t}_{1}\left[{ }^{\circ} \mathrm{C}\right]$ & $\mathrm{t}_{3}\left[{ }^{\circ} \mathrm{C}\right]$ & $\mathrm{V}_{1}[1 / \mathrm{min}]$ & $\mathrm{V}_{2}[1 / \mathrm{min}]$ \\
\hline \multirow{4}{*}{ 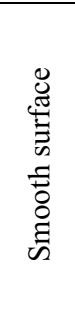 } & A1 (15) & 5 & $\begin{array}{l}14.86 \pm 0.42 \\
( \pm 0.10)\end{array}$ & $\begin{array}{l}39.67 \pm 0.47 \\
( \pm 0.14)\end{array}$ & $\begin{array}{c}2.50-9.77 \\
( \pm 0.02)\end{array}$ & $\begin{array}{c}7.20 \pm 0.06 \\
( \pm 0.02)\end{array}$ \\
\hline & B1 (20) & 8 & $\begin{array}{c}14.69 \pm 0.43 \\
( \pm 0.08)\end{array}$ & $\begin{array}{l}40.23 \pm 0.50 \\
\quad( \pm 0.13) \\
\end{array}$ & $\begin{array}{c}3.09-12.78 \\
( \pm 0.02) \\
\end{array}$ & $\begin{array}{c}7.20 \pm 0.04 \\
( \pm 0.02) \\
\end{array}$ \\
\hline & C1 (25) & 10 & $\begin{array}{l}15.21 \pm 0.45 \\
( \pm 0.11)\end{array}$ & $\begin{array}{l}40.04 \pm 0.63 \\
\quad( \pm 0.13)\end{array}$ & $\begin{array}{c}4.37-13,00 \\
( \pm 0.02)\end{array}$ & $\begin{array}{l}7.20 \pm 0.04 \\
( \pm 0.02)\end{array}$ \\
\hline & A2 (30) & 7 & $\begin{array}{c}15.16 \pm 0.52 \\
( \pm 0.14)\end{array}$ & $\begin{array}{l}39.9 \pm 0.41 \\
( \pm 0.20)\end{array}$ & $\begin{array}{c}3.50-12.08 \\
( \pm 0.02)\end{array}$ & $\begin{array}{c}7.21 \pm 0.04 \\
( \pm 0.03)\end{array}$ \\
\hline \multirow{4}{*}{ 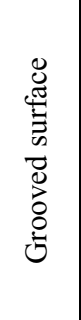 } & A1 (15) & 11 & $\begin{array}{c}15.06 \pm 0.53 \\
( \pm 0.10)\end{array}$ & $\begin{array}{l}40.06 \pm 0.59 \\
( \pm 0.11)\end{array}$ & $\begin{array}{c}3.02-11.80 \\
( \pm 0.02)\end{array}$ & $\begin{array}{c}7.19 \pm 0.06 \\
( \pm 0.02)\end{array}$ \\
\hline & B1 (20) & 8 & $\begin{array}{c}14.98 \pm 0.59 \\
( \pm 0.10)\end{array}$ & $\begin{array}{l}40.15 \pm 0.58 \\
( \pm 0.11)\end{array}$ & $\begin{array}{c}2.09-12.66 \\
( \pm 0.03)\end{array}$ & $\begin{array}{c}7.24 \pm 0.04 \\
( \pm 0.03)\end{array}$ \\
\hline & C1 (25) & 9 & $\begin{array}{c}15.15 \pm 0.33 \\
( \pm 0.11)\end{array}$ & $\begin{array}{l}40.38 \pm 0.44 \\
( \pm 0.13)\end{array}$ & $\begin{array}{c}3.17-13.24 \\
( \pm 0.02)\end{array}$ & $\begin{array}{c}7.21 \pm 0.04 \\
( \pm 0.02)\end{array}$ \\
\hline & A2 (30) & 12 & $\begin{array}{l}15.14 \pm 0.51 \\
( \pm 0.07)\end{array}$ & $\begin{array}{l}40.12 \pm 0.43 \\
\quad( \pm 0.16)\end{array}$ & $\begin{array}{c}2.95-13.45 \\
( \pm 0.02)\end{array}$ & $\begin{array}{c}7.21 \pm 0.04 \\
( \pm 0.01)\end{array}$ \\
\hline \multirow{3}{*}{ 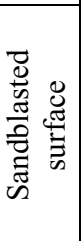 } & B1 (20) & 10 & $\begin{array}{l}15.08 \pm 0.36 \\
( \pm 0.09)\end{array}$ & $\begin{array}{l}40.34 \pm 0.33 \\
( \pm 0.16)\end{array}$ & $\begin{array}{c}2.53-11.97 \\
( \pm 0.02)\end{array}$ & $\begin{array}{c}7.20 \pm 0.03 \\
( \pm 0.03)\end{array}$ \\
\hline & C1 (25) & 10 & $\begin{array}{l}15.41 \pm 0.37 \\
( \pm 0.10)\end{array}$ & $\begin{array}{l}40.17 \pm 0.32 \\
\quad( \pm 0.11)\end{array}$ & $\begin{array}{c}2.97-12.59 \\
( \pm 0.02)\end{array}$ & $\begin{array}{c}7.21 \pm 0.03 \\
( \pm 0.01)\end{array}$ \\
\hline & A2 (30) & 10 & $\begin{array}{c}15.35 \pm 0.14 \\
( \pm 0.09)\end{array}$ & $\begin{array}{c}39.72 \pm 0.44 \\
( \pm 0.15)\end{array}$ & $\begin{array}{c}3.03-11.81 \\
( \pm 0.01)\end{array}$ & $\begin{array}{c}7.23 \pm 0.05 \\
( \pm 0.02)\end{array}$ \\
\hline
\end{tabular}




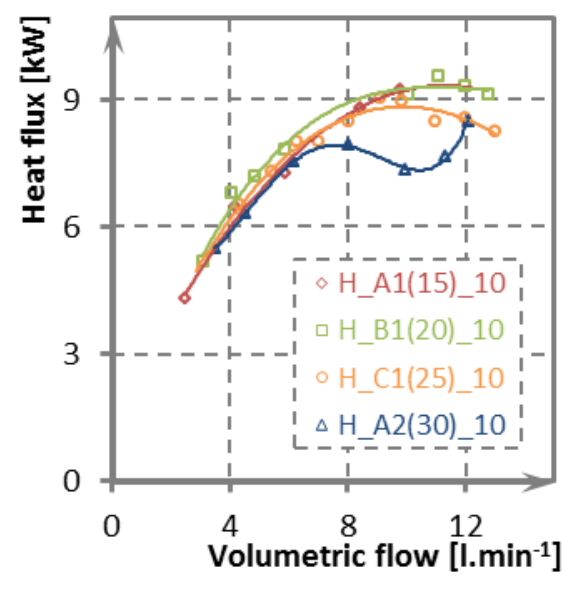

Figure 4 Dependence of Heat Transfer at Smooth Tubes

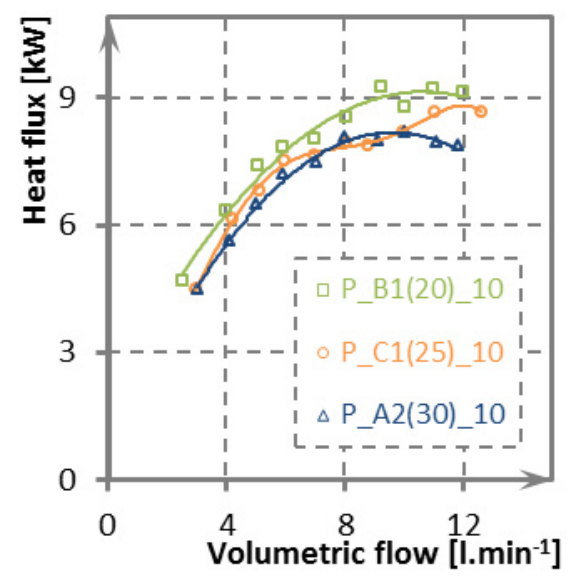

Figure 5 Dependence of Heat Transfer at Sandblasted Tubes

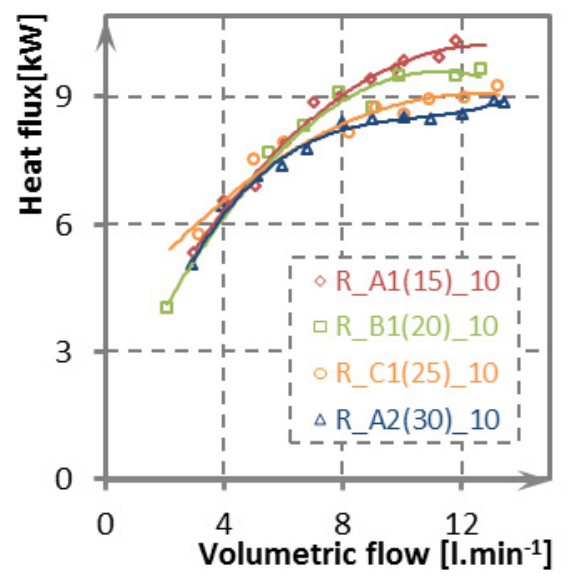

Figure 6 Dependence of Heat Transfer at Groove-Surface Tubes
With an increasing falling film liquid flow rate all waveforms are identical, i.e. approximately linearly rising. Within the flow rate range of approx. 6.0-9.5 litres per minute the heat transfer at individual surfaces and pitches stabilizes. With an increasing falling film liquid flow rate the total derived heat transfer ceases to rise or even slightly decreases at maximum measured flow rate. From this perspective the $\mathrm{A} 1$ and $\mathrm{B} 1$ tube pitch are convenient at smooth tubes where the maximum is around $9.5 \mathrm{~kW}$. The smallest A1 pitch has not been tested at sandblasted tubes and the maximum at the $\mathrm{B} 1$ pitch was achieved at the level of $9.2 \mathrm{~kW}$, which is approx. $0.2 \mathrm{~kW}$ less in comparison with smooth tubes. Groovesurface tubes proved most convenient in this experiment, in particular the A1 pitch, where the heat transfer was stabilized at the latest and at the level of approx. $10.4 \mathrm{~kW}$.

Thermographic camera sequences were captured at the above mentioned selected stabilized conditions that recorded dynamic alterations of temperature field at the surface of a sprinkled tube bundle. As displayed in Table 1, there were 30 sequences in total recorded in case of smooth tubes, 30 sequences as well at sandblasted tubes and 40 sequences at groove-surface tubes. The recording of each sequence lasted 6 seconds with the capture frequency of $30 \mathrm{~Hz}$. It means that each sequence contained 181 images. In Figure 7 you can find examples of images selected from the recorded sequences at the groove-surface tube bundle and the B1 tube pitch $(20 \mathrm{~mm})$. The flow rate at which the sequence was recorded is given in the bottom corner of each image and its unit of measurement is litres per minute. All thermographic images in this paper follow the same colour scheme displayed in Figure 7 in the bottom righthand corner, where white colour represents $42.0^{\circ} \mathrm{C}$ and black colour represents $14.0^{\circ} \mathrm{C}$. A part of a distribution tube is visible by the top edge of each image with falling film liquid flowing out of it. A falling film liquid collection flume that conducts the liquid towards a measuring thermocouple is visible at the bottom part of each image. When looking at individual images the liquid performance at various flow rates can be observed. At a high falling film liquid flow rate the liquid film is evenly spread along the first tubes, however, at the other tubes the liquid tends to use only a part of the tube bundle and flows in streams that merge at the last rows. Due to this the actual liquid film, or a marginal layer, is thick. In the range of approx. 5.0-8.0 1/min the liquid is already spread evenly along the whole bundle surface. At a low flow rate, as visible in the figures, the real heating occurs only at the third and fourth row and other rows are already redundant. 


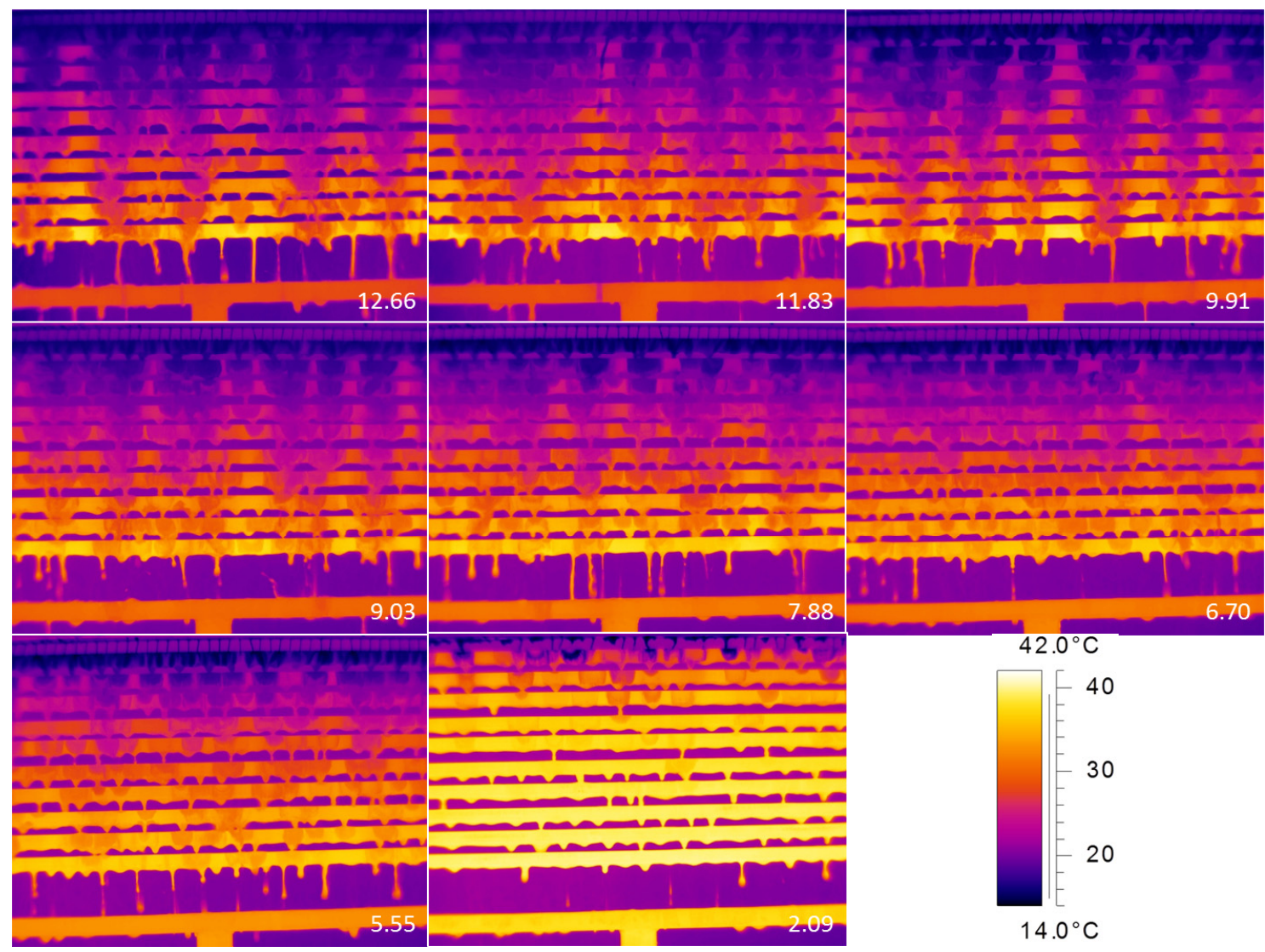

Figure 7 Examples of Images of Recorded Sequences at Groove-Surface Tube Bundle with B1 Pitch (20)

In order to be able to compare individual sequences and quantify alterations of temperature field, an algorithm has been created in the Matlab R2010b software. First of all, a representative area was selected in the image and areas where individual tubes were positioned were highlighted. Figure 8 is an example of such an image.

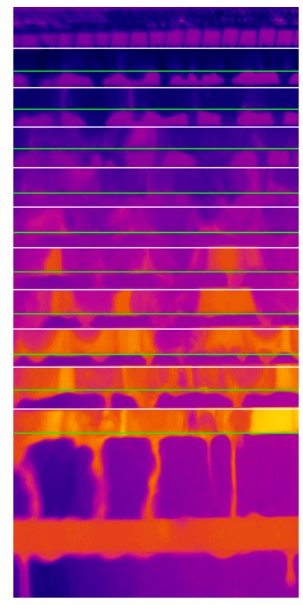

Figure 8 Examples of Image with Borders of Areas Studied

The top border of the tube is highlighted by a while line and the bottom border is highlighted by a green line. Temperature difference between these borders was measured at individual tubes in each image. Their number in each section depended on the pitch studied, i.e. the bigger pitch, the further the thermographic camera was positioned from the tube bundle and the fewer points were measured. At the A1 pitch the number of values in one section (at one tube) in one image was around 75 thousand, at the B1 pitch it was 40 thousand, at the $\mathrm{C} 1$ pitch it was 31 thousand and at the A2 pitch it was approx. 28 thousand. Total number of values in one sequence therefore ranged between approx. 51-136 million. These values for each tube in the given sequence were used to calculate an average and a standard deviation which represents the dispersion of temperatures containing an average temperature and according to which the stability of a temperature field at the surface of a sprinkled tube bundle in a certain area as well as the spread of liquid film can be determined. Thus two collections of values were created with each collection containing a thousand values. Calculated values were arranged into contour diagrams for a better comprehension divided according to a surface type and a tube bundle pitch. Figure 9 shows temperature differences as the falling film liquid temperature was not constant with partial flow rates studied and the temperature value at the first tube was deducted from the temperature at the other tubes. Figure 10 shows maps of standard deviations. Both diagrams feature the " $y$ " axis as the falling film liquid flow rate and the " $\mathrm{x}$ " axis as the tube number where number one represents the first tube in the direction of falling film liquid flow, i.e. the top one, and number ten represents the last tube.

These images imply partial differences both between surface types and between individual pitches. The differences between a smooth and a sandblasted tube at two falling film liquid flow rates are for a better understanding given here. Figure 11 shows the first example situation at the flow rate of approx. $9.8 \mathrm{l} / \mathrm{min}$. 


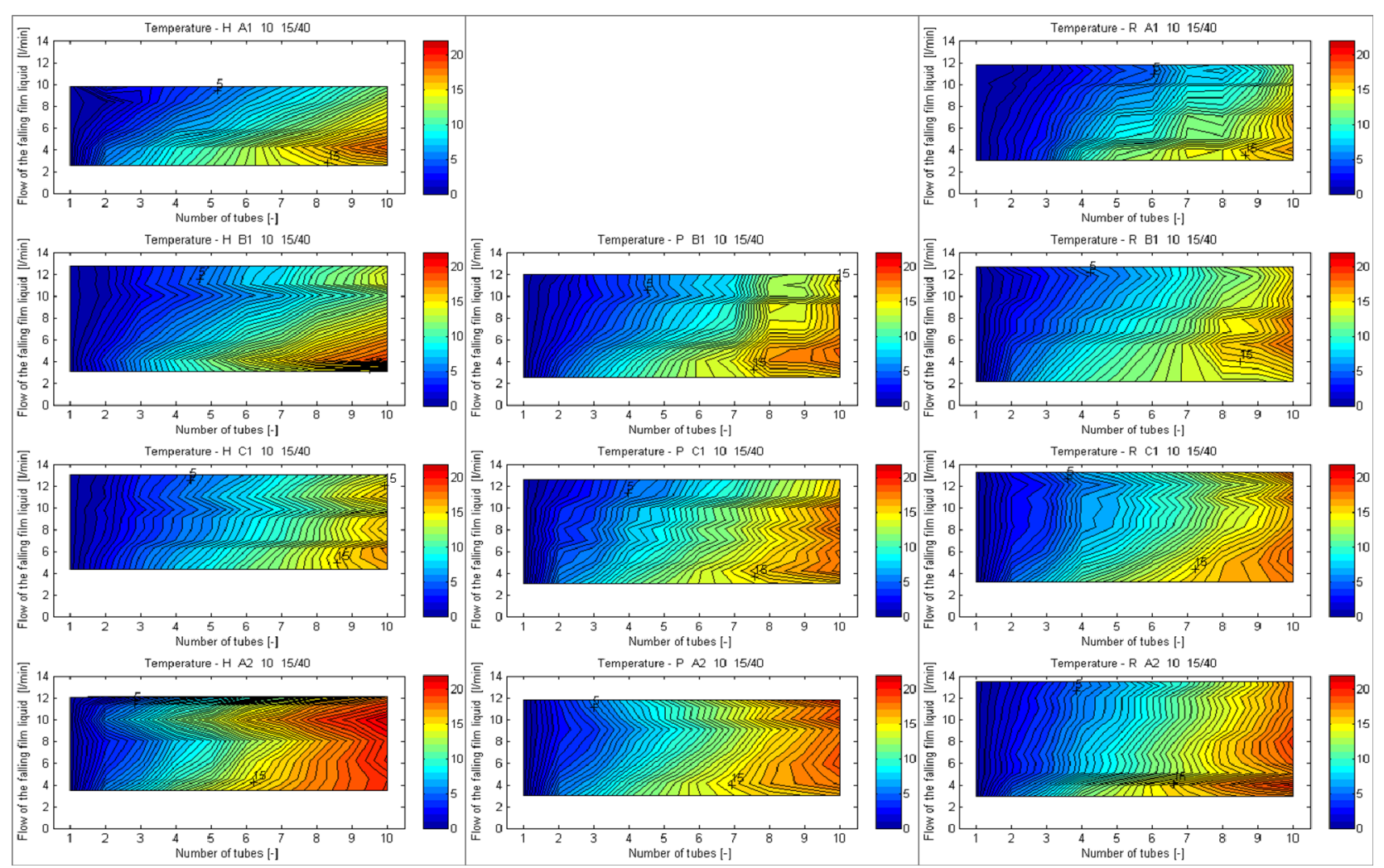

Figure 10 Temperature Fields

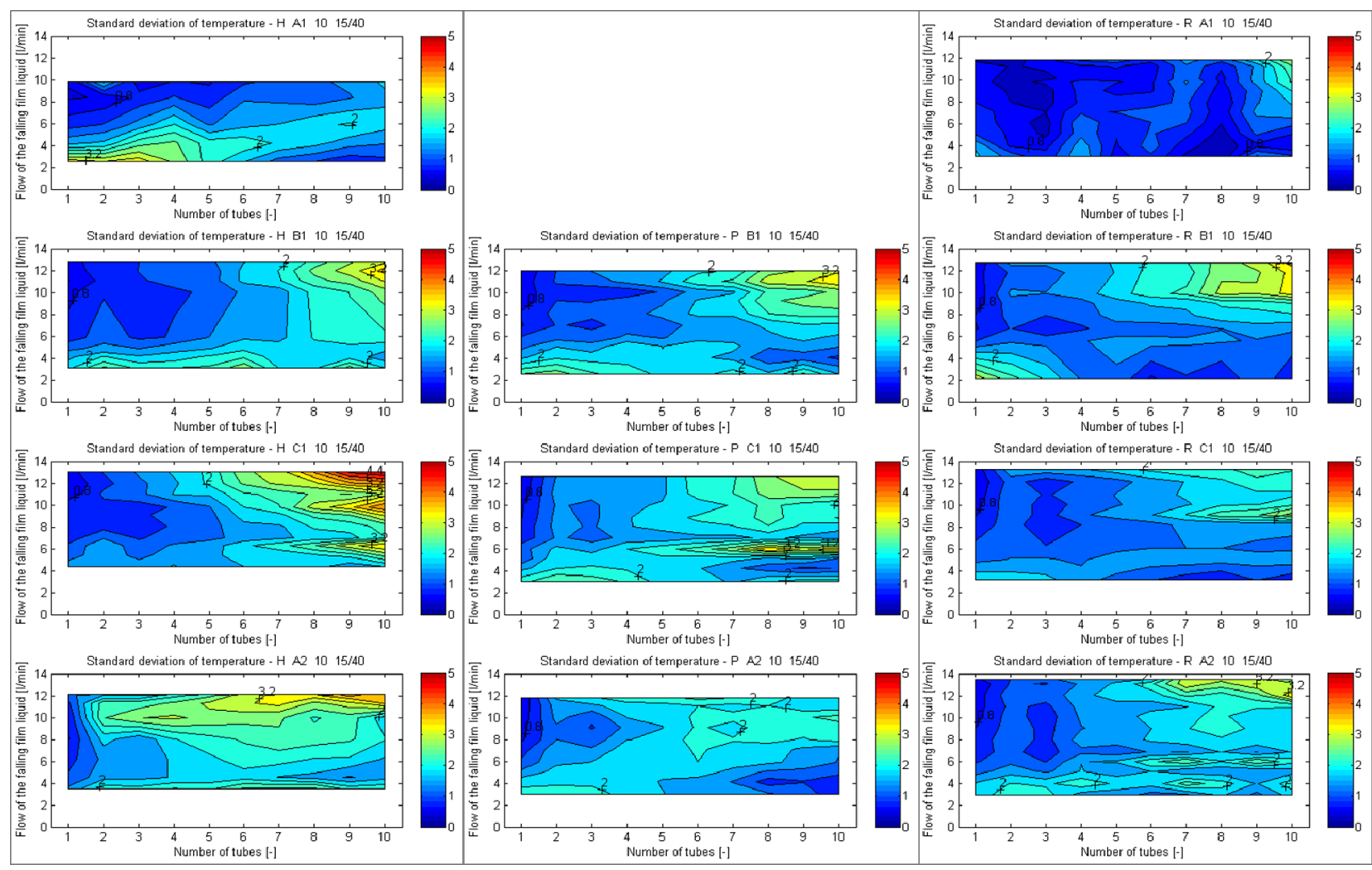

Figure 10 Standard Temperature Deviations

In the top of the image there is a tube bundle with a smooth surface and in the bottom there is a bundle with a grooved surface. From the point of view of a liquid film spread it is clear that at the first tube the liquid is distributed evenly at both surface types. At a smooth surface, however, the liquid consequently tends to narrow a real flow area and forms streams which result in a thickening of the film, i.e. of marginal layers. The whole bundle is still covered by a liquid film and no part of the tube is dry. To the contrary, a grooved surface causes the liquid film to spread evenly along the whole bundle. As a result, not only the temperature 
difference at a grooved surface but also the total heat transfer is higher. The diagram of standard deviations also clearly shows that the standard deviation at the last two rows is quite high too which is caused by the fact that the last two tubes are not fully used.

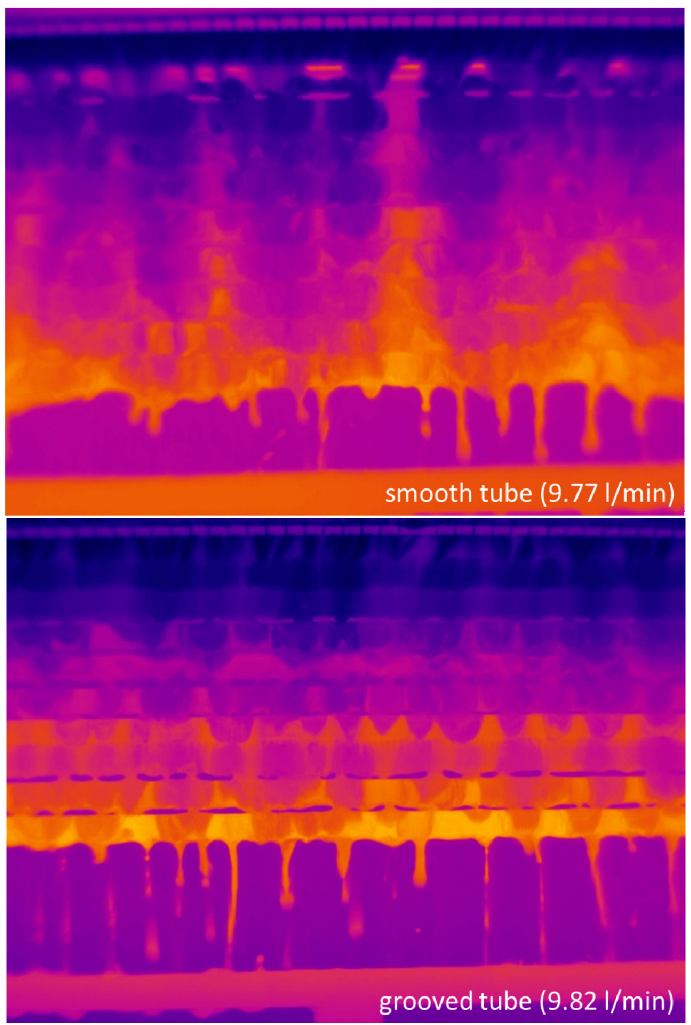

Figure 11 Temperature Fields Difference at High Flow Rate

The second example is the difference at a low flow rate. Images are visible at Fig. 12 where the flow rate was $2.5 \mathrm{l} / \mathrm{min}$ at smooth tubes and $3.0 \mathrm{l} / \mathrm{min}$ at groove-surface tubes.

At this flow rate it is evident that the larger part of the bundle is completely unused which is in case of the last tubes visible from low values in the standard deviation diagrams. The first smooth tubes demonstrate the contrary where the liquid tends to flow in streams only in certain areas and due to this the standard deviations are high. Even two dry areas can be spotted on the second tube. Contrary to this, liquid at a grooved surface remains evenly spread along the whole height of the bundle.

Diagrams with standard deviations must be divided into two groups for assessment. At a low flow rate the standard deviation is low at a liquid that has already been heated and this part of the bundle is actually no longer used. Contrary to this, at a high flow rate the high standard deviation occurs at a liquid film where the liquid is spread unevenly and in reality flows only in certain areas and does not use the surface of the whole bundle. It is more difficult to assess optimal spread at temperature differences, i.e. it is possible to compare the heating of a liquid and borders when boiling no longer occurs.

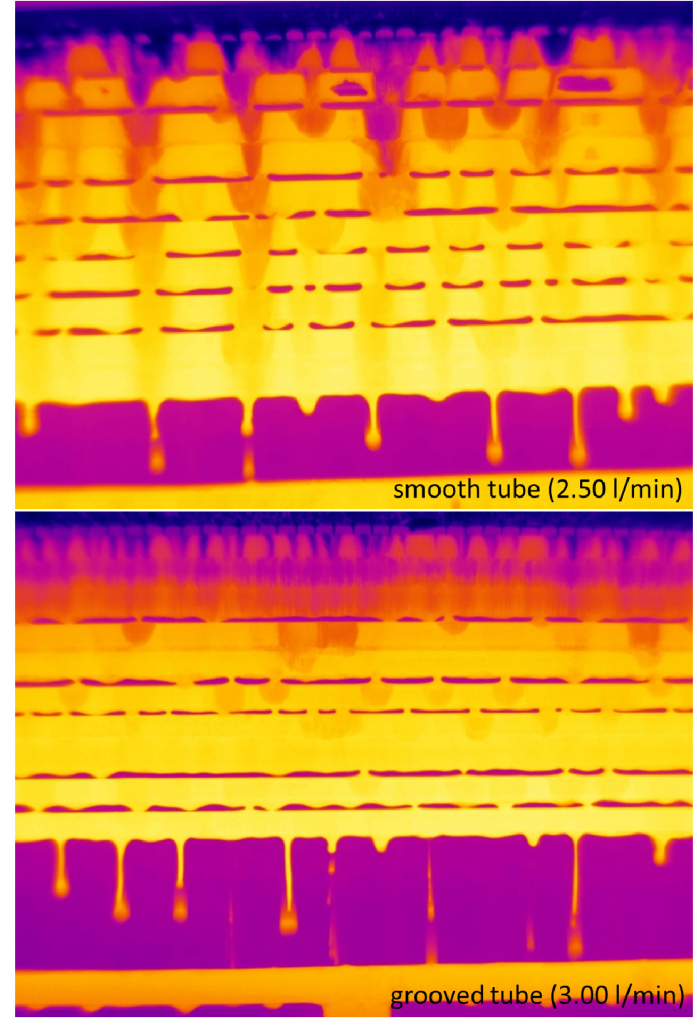

Figure 12 Temperature Fields Difference at Low Flow Rate

At a smooth surface gradual heating of the falling film liquid surface can be observed where temperature difference at the $\mathrm{A} 1$ pitch was higher than $16^{\circ} \mathrm{C}$ at the flow rate of approx. $71 / \mathrm{min}$ at $9^{\text {th }}$ tube and gradually approached to $7^{\text {th }}$ tube when the flow rate was decreased. At the flow rate around $4.01 / \mathrm{min}$ the temperature difference was more than $18{ }^{\circ} \mathrm{C}$ at $9^{\text {th }}$ tube. With an increasing tube pitch this area extended and at the same time grew more even. At the $\mathrm{C} 1$ pitch the temperature difference did not reach the temperature of $18^{\circ} \mathrm{C}$ but at the last two or three rows the temperature difference was identically spread and exceeded $16{ }^{\circ} \mathrm{C}$. At the A2 pitch this area extended up to the sixth row while the maximum was reached at approx. $8^{\text {th }}$ or $9^{\text {th }}$ row. At a sandblasted surface an indication of an even spread in relation to the falling film liquid flow rate was more noticeable in comparison with smooth tubes. Heating of the falling film liquid surface, i.e. the temperature difference higher than $18{ }^{\circ} \mathrm{C}$, was reached only at the A2 pitch, but in an insignificant extent. From this perspective the groove-surface tube bundle proved the most convenient where the spread was even along the whole range of pitches and heating by more than $18{ }^{\circ} \mathrm{C}$ was achieved at the flow rate of $7.51 / \mathrm{min}$ and sooner than at the ninth or tenth tube while this area extended at the A2 pitch up to the seventh tube at the flow rate of $4.0 \mathrm{l} / \mathrm{min}$ and lower. 


\section{Conclusions}

This paper presents partial results of research of temperature fields at a sprinkled tube bundle recorded by a thermographic camera. A tube bundle consisted of ten smooth copper tubes of the $12.0 \mathrm{~mm}$ diameter with a studied tube length one meter and with the tube pitch of $20.0 \mathrm{~mm}$. The measured relations of temperature differences, i.e. the heat transfer to the falling film liquid, an increasing trend up to approx. 6.0-9.5 1/min is evident. Afterwards individual quantities stabilized and values ceased to rise with an increasing flow rate, but to the contrary in some cases even decreased slightly.

Spread of liquid at a tube bundle is visible from thermographic image examples of individual sequences. At the maximum flow rate at the first tubes the spread of water was even with respect of its distribution and a real used surface at the other tubes diminished in spite of the fact that the tubes were covered by a liquid film. I.e. by narrowing the used part of an exchanger the film thickness grew and therefore the heat transfer stabilized and ceased to rise. This phenomenon is clearly visible in the contour diagrams as well where the last tubes demonstrate high standard deviation. This performance can be assigned to surface tension influences of the liquid that aims to spread over the most convenient area in order to decrease its surface tension. On these grounds the optimal range of falling film liquid flow rate for the given exchangers can be determined and it ranges between approx. 5.0 and 10.0 litres per minute.

With further decreasing of a flow rate the mean exchanger temperature rises but it is accompanied by the standard deviation increase as well. I.e. exchangers as such are not used to their full potential and their surface is redundant. At the lowest flow rate at smooth tubes the liquid film even ceases to exist at some areas of the last tubes. When comparing the results between various surfaces the most convenient one clearly is the grooved one, both from the point of view of heat transfer and liquid spread in an exchanger.

Tube bundles with sandblasted surface brought surprising results. Heat transfer is slightly lower or identical to a smooth surface, although the falling film liquid spread is better at the exchanger's surface although it does not achieve the results of a grooved surface. Among testing other parameters influencing the heat transfer at a sprinkled tube bundle, our aim for the next research will be to discover the reason of less convenient results of a sandblasted surface.

\section{Acknowledgement}

The authors gratefully acknowledge a financial support from the project ED0002/01/01 - NETME CENTRE, NETME CENTRE PLUS (LO1202) and Specific Research Project FSI-S-14-2403 Complex Research on Combustion and Heat Recovery Equipment provided by Faculty of Mechanical Engineering, Brno University of Technology.

\section{References}

1. R. Armbruster, J. Mitrovic, Experimental Thermal and Fluid Science, vol. 18, no. 3, pp. 183-194 (1998)

2. R. Armbruster, J. Mitrovic, Proceedings of the 10th international heat transfer conference: Brighton, UK, no. 3, pp. 275-280 (1994).

3. J. Beniak, J. Ondruška, V. Čačko, Acta Polytechnica, vol. 52, no. 5, pp. 133-137 (2012)

4. J. Beniak, P. Križan, M. Matúš, M. Kováčová, Acta Polytechnica, vol. 54, no. 1, pp. 1-5 (2014)

5. X. Hu, A. M. Jacobi, Journal of Heat Transfer, vol. 118, no. 3, pp. 616-624 (1996)

6. L.-H. Chien, Ch.-H. Cheng, HVAC, vol. 12, no. 1, pp. 69-87 (2006)

7. J. J. Lorenz, D. Yung, Journal of Heat Transfer, vol. 101, no. 1, pp. 178-180 (1979)

8. W. L. Owens, Proceedings, Fifth Ocean Thermal Energy Conversion Conference, Miami Beach, Florida, pp. 71-89 (1978)

9. W. H. Parken, L. S. Fletcher, V. Sernas, J. C. Han, Journal of Heat Transfer, vol. 112, no. 3, pp. 744-750 (1990)

10. J. F. Roques, V. Dupont, J. R. Thome, Journal of Heat Transfer, vol. 124, no. 3, pp. 491-499 (2002)

11. V. Sernas, Journal of Heat Transfer, vol. 101, no. 1, pp. 176-178 (1979) 